\begin{tabular}{ll}
\hline JURNAL PELITA PENDIDIKAN & $\begin{array}{l}\text { Volume } 7 \text { Nomor } 1 \text { (2019) } 016 \text { - } 022 \\
\text { Jurnal Pelita Pendidikan } \\
\text { Journal of Biology Education } \\
\text { https://jurnal.unimed.ac.id/2012/index.php/pelita/index }\end{array}$ \\
\hline
\end{tabular}

\title{
EFEKTIVITAS MODEL COMPLETE SENTENCE BERBANTU MEDIA AUDIO VISUAL TERHADAP HASIL DAN AKTIVITAS BELAJAR SISWA PADA MATERI SISTEM REPRODUKSI MANUSIA
}

\author{
Ayu Marsela ${ }^{1}$, Adriana Y. D. Lbn. Gaol ${ }^{1}$, Herawati Dongoran ${ }^{2}$ \\ ${ }^{1}$ Program Studi Pendidikan Biologi, Fakultas Matematika dan Ilmu Pengetahuan Alam, Universitas Negeri Medan, \\ Jalan Willem Iskandar Pasar V Medan Estate 20221, Sumatera Utara, Indonesia \\ ${ }^{2}$ Guru Biologi MAN 1 Medan, Jalan Willem Iskandar No. 7B, Kecamatan Medan Tembung, Kota Medan, Sumatera \\ Utara 20222 \\ Korespondensi Author: ayumarsela08@gmail.com (Marsela)
}

\section{INFO ARTIKEL}

\section{Histori Artikel}

Received 24 Agustus 2018

Revised 15 Maret 2019

Accepted 15 Maret 2019

Published 7 Juli 2019

\section{Keywords:}

Audio Visual Media, Complete Sentence Models, learning activities, learning outcomes

\begin{abstract}
This study aims to determine the effectiveness of Complete Sentence learning models assisted by audio visual media on student learning outcomes and activities on human reproductive system material in the State Madrasah Aliyah (MAN) 1 Medan 2017/2018 Learning Year. This type of research is pre-experimental, where the population of this study were all students of class XI MIA MAN 1 Medan, amounting to 8 classes. The sampling technique used is random sampling where the sample is class XI MIA 4, amounting to 45 people. The results showed that the level of mastery of students reached 88.6 including the high category, student learning completeness reached $91 \%$ including the complete category, achievement of indicators reaching 86.59 including categories achieved, and student learning activities which reached 75.55 included in the active category. So it can be concluded that the Complete Sentence learning model is assisted by effective audio visual media used in human reproductive system material in class $\mathrm{XI}$ MIA MAN 1 Medan 2017/2018 Learning Year.
\end{abstract}

\section{How to Cite:}

Marsela, A., Lbn.Gaol, AYD., Dongoran, H. (2019). Efektivitas Model Complete Sentence Berbantu Media Audio Visual terhadap Hasil dan Aktivitas Belajar Siswa pada Materi Sistem Reproduksi Manusia. Jurnal Pelita Pendidikan, 7(1), 016-022.

\section{PENDAHULUAN}

Kegiatan pembelajaran merupakan proses pendidikan yang memberikan kesempatan kepada peserta didik untuk mengembangkan potensi dirinya menjadi kemampuan yang semakin lama semakin meningkat dalam sikap, pengetahuan, dan keterampilan untuk hidup bermasyarakat, berbangsa, serta berkontribusi pada kesejahteraan hidup umat manusia. Kegiatan pembelajaran perlu menggunakan prinsip : (1) berpusat pada peserta didik; (2) mengembangkan kreativitas peserta didik; (3) 
menciptakan kondisi menyenangkan dan menantang; (4) bermuatan etika, estetika, logika, dan kinestetika; dan (5) menyediakan pengalaman belajar yang beragam melalui variasi metode dan strategi pembelajaran di kelas maupun di luar kelas (Suharno,2014).

Lahirnya kurikulum 2013 dengan ciri khas pembelajaran kompetensi dengan memperkuat proses pembelajaran dan penilaian autentik untuk mencapai kompetensi sikap, pengetahuan dan keterampilan adalah sangat tepat. Penguatan proses pembelajaran dilakukan melalui pendekatan saintifik, yaitu pembelajaran yang mendorong siswa lebih mampu dalam mengamati, menanya, mencoba/ mengumpulkan data, mengasosiasi/menalar, dan mengomunikasikan (Hariyatmi dan Syaifullah, 2016).

Meskipun saat ini hampir disemua sekolah sudah menerapkan kurikulum 2013 namun masih kurang maksimal dalam pelaksanaannya, misalnya pembelajaran yang memicu siswa aktif hanya dengan metode diskusi dan tanya jawab sedangkan guru kurang menerapkan model pembelajaran yang bervariasi. Guru cenderung mempergunakan model pembelajaran langsung, karena dinilai lebih praktis dan lebih mudah mencapai tujuan pembelajaran. Akibatnya pembelajaran bersifat berpusat pada guru, bukan pada siswa. Guru bertindak sebagai pentransfer pengetahuan yang mereka yakini benar(Suharno,2014).

Upaya untuk meningkatkan kualitas siswa, guru diharapkan mampu mengimplementasikan metode pembelajaran yang inovatif (students-centered) dengan cara menerapkan model pembelajaran yang bervariasi atau dengan menggunakan media pembelajaran, hal ini disebabkan pembelajaran konvensional (teacher-centered) dianggap tidak lagi mampu memenuhi kriteria kurikulum 2013. Agar siswa mampu mengembangkan sikap dan pengalaman sesuai dengan perbedaan potensinya, maka peran guru tidak lagi sebagai pentransfer ilmu, melainkan sebagai fasilitator atau membantu siswa agar siswa mampu menguasai berbagai kompetensi yang diharapkan (Qomariyah,2014). Strategi pembelajaran merupakan suatu kegiatan pembelajaran yang harus dikerjakan oleh guru dan siswa agar tujuan pembelajaran dapat dicapai secara efektif dan efisien (Hasruddin dkk, 2016).

Model pembelajaran merupakan perencanaan atau suatu pola yang digunakan sebagai pedoman dalam merencanakan pembelajaran di kelas yang mengacu pada pendekatan pembelajaran yang akan digunakan, termasuk didalamnya tujuan-tujuan pengajaran, tahap-tahap dalam kegiatan pembelajaran, lingkungan pembelajaran dan pengelolaan kelas (Riyadi dkk, 2015). Complete sentence adalah pembelajaran dengan model melengkapi kalimat. Model pembelajaran ini merupakan model pembelajaran yang inovatif, siswa belajar melengkapi paragraf yang belum lengkap kalimatnya (Winarti, 2017). Model ini juga merupakan model yang praktis, terarah dan cukup efektif (Marumu, 2015).

Media merupakan segala sesuatu yang dapat menyalurkan pesan dari orang yang memberi pesan kepada orang yang menerima pesan baik berupa perangkat keras ataupun perangkat lunak. Salah satu media yang dapat digunakan adalah media audio visual. Penggunaan media audio visual dapat mempertinggi perhatian anak dengan tampilan yang menarik. Selain itu, anak akan takut ketinggalan jalannya video tersebut jika melewatkan dengan mengalihkan konsentrasi dan perhatian. Media audio visual yang menampilkan realitas materi dapat memberikan pengalaman nyata pada siswa saat mempelajarinya sehingga mendorong adanya aktivitas diri (Fujiyanto dkk, 2016).

Salah satu materi dalam mata pelajaran biologi adalah sistem reproduksi. Materi sistem reproduksi membahas tentang struktur, fungsi serta proses-proses atau mekanisme yang berkaitan dengan sistem reproduksi dan terjadi didalam tubuh. Selain itu materi sistem reproduksi juga tidak dapat dipraktikumkan. Sehingga siswa kesulitan dalam memahami materi. Kemajuan teknologi memungkinkan suatu pembelajaran menggunakan media pembelajaran inovatif, salah satunya adalah dengan menggunakan media audio visual yang mampu menggambarkan materi pembelajaran secara lebih jelas dan sistematis, sehingga pembelajaran menjadi tidak abstrak. Hasil penelitian Utami dkk (2012) menunjukkan bahwa penggunaan media audio visual memiliki nilai rata-rata 87,88 dengan kreteria baik, sedangkan dengan media berbasis lingkungan memiliki nilai rata-rata 73,75 berada pada kategori cukup dengan perbedaan sebesar $10 \%$. Selain itu dalam penelitian Mukti dan Nurcahyo (2017) yang juga mendukung pernyataan di atas ialah mengemukakan bahwa 
penggunaan media audio visual menyebabkan peningkatan hasil belajar peserta didik dengan kategori tinggi dan presentase pencapaian ketuntasan belajar sebesar 83,33\%.

Selain itu materi sistem reproduksi banyak menggunakan istilah-istilah ilmiah sehingga cukup sulit bagi siswa untuk memahami dan mengingatnya. Oleh sebab itu, dibutuhkan suatu model pembelajaran yang dapat membantu siswa mempelajari materi secara runtut agar pemahaman siswa terhadap sistem reproduksi menjadi lebih mudah. Salah satu model yang tepat adalah Complete Sentence. Model pembelajaran Complete Sentence adalah model pembelajaran yang mengarahkan siswa belajar melengkapi paragraf yang belum sempurna yang disajikan dalam bentuk LKPD. Model Complete Sentence dapat menumbuhkan semangat dan motivasi siswa untuk mengikuti kegiatan pembelajaran. Dalam penelitian Fatimah (2016) medapatkan hasil pembelajaran pada subkonsep vertebrata dengan menggunakan model Complete Sentence $(82,93 \%)$ lebih baik dari Concept Sentence $(80,26 \%)$ walaupun perbedaannya tidak signifikan.

Berdasarkan hasil wawancara dengan salah satu guru di MAN 1 Medan, menurut penuturan Ibu Herawati Dongoran, S.Ag., M.Pd. selaku guru biologi disekolah tersebut mengatakan bahwa metode yang digunakan adalah ceramah, diskusi, tanya jawab dan penugasan dan kurang dalam menerapkan model pembelajaran. Suasana belajar demikian akan menimbulkan rasa bosan siswa dalam menikuti pembelajaran, hal ini akan mempengaruhi hasil belajar siswa. Hasil belajar siswa sering kali belum mencapai nilai KKM yaitu 83 . Sebanyak $56 \%$ siswa yang memiliki nilai dibawah KKM atau sekitar 24-27 siswa dari 46 siswa yang tidak tuntas. Selain itu siswa umumnya sulit memahami materi sistem reproduksi karena banyak ulasan materi dan istilah biologi yang harus mereka baca dan ingat, ditambah lagi harus memahaminya dalam waktu yang singkat sehingga terkadang waktu yang tersedia tidak mencukupi untuk menuntaskan materi ini secara keseluruhan. Selain itu di MAN 1 Medan belum pernah diterapkan model pembelajaran Complete sentence.

Berdasarkan hasil observasi diketahui bahwa Madrasah Aliyah Negeri (MAN) 1 Medan memiliki fasilisitas multimedia yang cukup lengkap dan sumber daya manusia yang cukup baik. Hal ini dapat dilihat dari kemampuan guru dan siswa yang terampil dalam menggunakan fasilitas multimedia. Kondisi tersebut sangat mendukung suatu pembelajaran yang inovatif dengan memanfaatkan multimedia yang telah tersedia. Namun demikian, ketersediaan fasilitas multimedia disekolah tersebut kurang dimanfaatkan secara optimal dalam pembelajaran biologi karena dalam penggunaan media pembelajaran guru perlu mempersiapkan bahan ajar yang lebih banyak, misalnya dengan membuat animasi, mengunduh video pembelajaran dan lain-lain. Berdasarkan hal tersebut, model Complete Sentence berbantu media audio visual sangat penting digunakan untuk meningkatkan aktivitas belajar dan pemahaman konsep biologi siswa pada pokok bahasan system reproduksi manusia siswa kelas XI MIA 2 MAN 1 Medan.

\section{METODE PENELITIAN}

Pengumpulan data maupun informasi yang dibutuhkan dalam penelitian ini dilaksanakan di MAN 1 Medan. Penelitian dilakukan selama 6 bulan, pada bulan Januari Juni 2018. Populasi pada penelitian ini adalah kelas XI MIA MAN 1 Medan T.P 2017/2018. Sampel yang digunakan dalam penelitian adalah kelas XI MIA 4 yang berjumlah 45 orang dengan teknik Random Sampling.

Instrumen penelitian ini yaitu tes hasil belajar dan lembar observasi aktivitas belajar siswa. Jenis penelitian ini adalah penelitian praeksperimen, yang bertujuan untuk mengetahui fakta-fakta yang terjadi pada pembelajaran biologi dengan memberikan perlakuan terhadap satu kelompok siswa dengan menggunakan model pembelajaran Complete Sentence berbantu Media Audio Visual pada materi sistem reproduki manusia.

Teknik analisis data dilakukan dengan menghitung tingkat penguasaan siswa, ketuntasan belajar, tingkat ketercapaian indikator, dan kemampuan berpikir kreatif siswa

\section{HASIL DAN PEMBAHASAN}

Hasil pre-test siswa menunjukkan bahwa nilai tertinggi adalah 68 dan nilai terendah adalah 36. Sedangkan untuk hasil pos-test menunjukkan bahwa nilai tertinggi 100 dan nilai terendah adalah 68. Persentase peningkatan hasil belajar siswa adalah $36.61 \%$. 
Adanya peningkatan hasil belajar karena siswa telah memperoleh pengajaran sehingga dapat mengetahui dan memahami intisari dari materi sistem reproduksi manusia. Adapun ringkasan persentase hasil belajar siswa tersaji pada tabel 1 dibawah ini.

Tabel 1. Hasil Belajar Siswa

\begin{tabular}{cccccc}
\hline \multicolumn{5}{c}{ Hasil Belajar Siswa } \\
\hline \multicolumn{5}{c}{ Pre-test } & \multicolumn{3}{c}{ Post-test } \\
\hline Nilai & Frek & Rerata & Nilai & Frek & Rerata \\
\hline 36 & 1 & & 68 & 1 & \\
40 & 3 & & 72 & 3 & \\
44 & 1 & & 76 & 1 & \\
48 & 6 & & 80 & 1 & \\
52 & 5 & 56.1 & 84 & 5 & \\
56 & 13 & & 88 & 15 & 88.6 \\
60 & 1 & & 92 & 8 & \\
64 & 7 & & 96 & 7 & \\
68 & 8 & & 100 & 4 & \\
Jmlh & 45 & & Jmlh & 45 & \\
\hline
\end{tabular}

\section{Tingkat Penguasaan Siswa}

Berdasarkan hasil post-test diketahui bahwa terdapat 19 siswa (42.2\%) yang memperoleh tingkat penguasaan dengan kategori sangat tinggi, 21 siswa (46.6\%) yang memperoleh tingkat penguasaan dengan kategori tinggi, 4 siswa $(8.88 \%)$ yang memperoleh tingkat penguasaan dengan kategori sedang, 1 siswa (2.22\%) yang memperoleh tingkat penguasaan dengan kategori rendah dan tidak ada siswa $(0 \%)$ yang memperoleh tingkat penguasaan dengan kategori sangat rendah. Sedangkan dari skor rata - rata tingkat penguasaan siswa pada saat post-test adalah sebesar 88.6 sehingga dapat disimpulkan bahwa secara umum tingkat penguasaan siswa pada materi sistem reproduksi manusia di kelas XI MIA MAN 1 Medan Tahun Pembelajaran 2017/2018 setelah diberikan pengajaran dengan model pembelajaran Complete Sentence berbantu media audio visual tergolong kategori tinggi.

\section{Ketuntasan Belajar Siswa}

Dari hasil penelitian diperoleh ketuntasan hasil belajar 41 siswa atau 91\% dari keseluruhan siswa dinyatakan telah lulus dalam belajar karena telah memperoleh persentase tingkat penguasaan antara $75 \%$ - 100\%. Sedangkan secara klasikal (kelompok), kelas XI MIA MAN 1 Medan Tahun Pembelajaran 2017/2018 dinyatakan telah tuntas dalam belajar karena hanya 4 siswa yang tidak tuntas dalam belajar, yang berarti lebih dari $85 \%$ keseluruhan siswa yang sudah tuntas secara individual dan kelas tersebut dinyatakan tuntas secara klasikal (kelompok).

\section{Ketercapaian Indikator}

Untuk data ketercapaian indikator pada setiap materi, dapat di lihat pada Tabel 2 di bawah.

Tabel 2. Ketercapaian Indikator Pembelajaran

\begin{tabular}{|c|c|c|c|}
\hline No. & Indikator & $\begin{array}{c}\text { Rerata } \\
(\%)\end{array}$ & Kategori \\
\hline 1 & $\begin{array}{l}\text { Mengidentifikasi } \\
\text { strukutur dan fungsi } \\
\text { organ-organ sistem } \\
\text { reproduksi pada } \\
\text { manusia }\end{array}$ & 94.44 & Tercapai \\
\hline 2 & $\begin{array}{l}\text { Menjelaskan proses } \\
\text { pembentukan sel } \\
\text { kelamin pria dan } \\
\text { wanita serta hormon } \\
\text { sistem reproduksi }\end{array}$ & 89.13 & Tercapai \\
\hline 3 & $\begin{array}{l}\text { Menjelaskan proses } \\
\text { ovulasi dan } \\
\text { menstruasi }\end{array}$ & 87.22 & Tercapai \\
\hline 4 & $\begin{array}{l}\text { Mengidentifikasi } \\
\text { proses fertilisasi, } \\
\text { kehamilan dan } \\
\text { kelahiran. }\end{array}$ & 80 & Tercapai \\
\hline 5 & $\begin{array}{l}\text { Menjelaskan pengaruh } \\
\text { ASI dan kontrasepsi }\end{array}$ & 86 & Tercapai \\
\hline 6 & $\begin{array}{l}\text { Mengidentifikasi } \\
\text { penyakit yang terjadi } \\
\text { pada organ } \\
\text { reproduksi. }\end{array}$ & 82.78 & Tercapai \\
\hline
\end{tabular}

Berdasarkan tabel di atas dapat dilihat bahwa 6 indikator telah tercapai, sehingga dapat disimpulkan bahwa ketercapaian indikator yang diajukan dalam melaksanakan pembelajaran biologi pada materi sistem reproduksi manusia di kelas XI MIA 4 MAN 1 Medan Tahun Pembelajaran 2017/2018 secara keseluruhan tercapai.

\section{Hasil Observasi Aktivitas Belajar}

Data hasil observasi akativitas belajar siswa pada pertemuan 1,2 , 3, dan 4 dapat dilihat pada Tabel $3 \mathrm{~d}$ ibawah ini.

Tabel 3. Distribusi Frekuensi Skor Rata - rata Aktivitas Belajar Siswa

\begin{tabular}{cccc}
\hline No. & Skor & Kategori & Frekuensi \\
\hline 1 & $85-100$ & Sangat aktif & 8 \\
2 & $70-84$ & Aktif & 22 \\
3 & $55-69$ & Cukup aktif & 13 \\
4 & $0-54$ & Kurang aktif & 2 \\
\hline
\end{tabular}


Berdasarkan hasil aktivitas belajar siswa yang diperoleh dengan menggunakan model pembelajaran Complete Sentence berbantu media audio visual menunjukkan skor rata-rata aktivitas belajar siswa mencapai nilai 75.55 yang termasuk ke dalam kategori aktif. Skor rata-rata aktivitas belajar siswa di kelas XI MIA MAN 1 Medan dengan menggunakan model pembelajaran complete sentence berbantu media audio visual pada materi sistem reproduksi manusia adalah 8 siswa termasuk ke dalam kategori sangat aktif ( 85 - 100), 22 siswa termasuk ke dalam kategori aktif $(70-84), 13$ siswa termasuk ke dalam kategori cukup aktif (55 - 69), dan 2 siswa termasuk ke dalam kategori kurang aktif $(0-55)$.

\section{PEMBAHASAN}

Dalam penelitian ini tolak ukur keberhasilan penggunaan suatu model pembelajaran yang digunakan adalah hasil belajar yang terdiri dari tiga hal yaitu: 1) Tingkat Penguasaan Siswa, 2) Ketuntasan Belajar, dan 3) Ketercapian Indikator.

Berdasarkan deskripsi data hasil penelitian dapat dijelaskan beberapa hal mengenai penelitian ini. Sebelum dilaksanakan pengajaran menggunakan model pembelajaran Complete Sentence berbantu media audio visual, peneliti terlebih dahulu memberikan pre-test kepada siswa berupa soal.Dari hasil pre-test tersebut diketahui bahwa tidak ada siswa yang tergolong ke dalam kategori sangat tinggi, tinggi dan sedang.Seluruh siswa tergolong ke dalam kategori sangat rendah dan rendah.Rendahnya tingkat penguasaan siswa pada saat pre-test tersebut karena siswa masih belum mendapatkan pengajaran mengenai materi sistem reproduksi manusia.

Menurut Pujiati (2008) dari segi hasil, proses pembelajaran dikatakan berhasil apabila terjadi perubahan perilaku yang positif pada diri peserta didik seluruhnya atau setidaktidaknya sebagian besar (75\%). Dari hasil penelitian ini, model pembelajaran Complete Sentence berbantu media audio visual memberi pengaruh dalam persentase peningkatan hasil belajar siswa yang cukup signifikan yaitu $36.61 \%$ dengan nilai rata-rata 88.6 dengan 41 siswa (91\%) mengalami peningkatan nilai, dengan demikian proses pembelajaran dapat dikatakan berhasil.Adanya peningkatan tingkat penguasaan siswa pada materi sistem reproduksi manusia setelah post-test disebabkan karena siswa telah memperoleh pengajaran mengenai materi tersebut dengan menggunakan model dan media yang tepat sehingga siswa telah mengetahui dan memahami intisari dari materi sistem reproduksi manusia. Hal ini sesuai dengan pendapat Slameto (2015) alat pelajaran yang lengkap dan tepat akan memperlancar penerimaan bahan pelajaran yang diberikan kepada siswa. Hal ini sesuai dengan hasil penelitian Utami dkk (2012) yang menunjukkan bahwa penggunaan media audio visual memiliki nilai rata-rata87,88 dengan kreteria baik, sedangkan dengan media berbasis lingkungan memiliki nilai ratarata73,75 berada pada kategori cukup dengan perbedaan sebesar $10 \%$. Selain itu dalam penelitian Mukti dan Nurcahyo (2017) yang juga mendukung pernyataan di atas ialah mengemukakan bahwa penggunaan media audio visual menyebabkan peningkatan hasil belajar peserta didik dengan kategori tinggi dan presentase pencapaian ketuntasan belajar sebesar 83,333\%. Hal tersebut juga sejalan dengan penelitian Fatimah (2016) yang mendapatkan hasil pembelajaran pada subkonsep vertebrata dengan menggunakan model Complete Sentence (82,93\%) lebih baik dari Concept Sentence $(80,26 \%)$ walaupun perbedaannya tidak signifikan.

Tingkat penguasaan siswa yang diberi pengajaran menggunakan model complete sentence berbantu media audio visual dalam penelitian ini sudah termasuk kedalam kategori tinggi. Hal ini sesuai dengan pendapat Arifin (2009) yang menyatakan bahwa untuk mengetahui sejauh mana tingkat penguasaan siswa terhadap pembelajaran sistem reproduksi manusia digunakan prinsip konversi lima.Dalam skala tersebut apabila persentase penguasaan siswa mencapai $80-89 \%$ maka penguasaan siswa termasuk ke dalam kategori tinggi.Menurut Supardi (2013) mutu hasil pendidikan sebagian besar ditentukan oleh mutu kegiatan belajar-mengajar.Mutu professional guru harus terlihat pada kemampuannya mengelola kelas dan mengajar secara efektif dalam arti dia mampu membelajarkan para siswa menguasai bahan pelajaran yang diberikannya sesuai dengan tuntutan kurikulum.Dengan demikian kriteria tingkat penguasaan siswa pada pembelajaran biologi dengan menggunakan model complete sentence berbantu media audio visual telah terpenuhi. 
Untuk ketuntasan belajar, menurut Pujiati (2008) Setiap siswa harus mampu menguasai kompetensi-kompetensi dasar (basic learning objectives) secara tuntas, yakni sekurang-kurangnya harus mencapai skor minimal 75. Hasil penelitian untuk ketuntasan belajar siswa, diperoleh hasil bahwa baik secara individu maupun secara klasikal siswa kelas XI MIA MAN 1 Medan Tahun Pembelajaran 2017/2018 dinyatakan tuntas dalam belajar. Hasil ini terlihat dari perolehan nilai siswa yang telah mencapai nilai antara 75-100, dimana terdapat 39 siswa yang telah tuntas dalam belajar dan 6siswa lainnya tidak tuntas dalam belajar. Persentase ketuntasan belajar secara klasikal telah mencapai $86.6 \%$ yang berarti telah memenuhi standar minimal tercapainya ketuntasan belajar secara klasikal.

Sementara untuk ketercapaian indikator diketahui bahwa seluruh materi pembelajaran yang terdiri dari 4 indikator yang ingin dicapai dengan menggunakan model pembelajaran Complete Sentence berbantu media audio visual telah tercapai dengan baik.Hal ini sesuai dengan pendapat Suryosubroto (2007) ketuntasan indikator (tujuan pembelajaran) adalah apabila paling sedikit $75 \%$ dari seluruh indikator yang sudah ditentukan sudah tercapai.

Dari hasil penelitian dan pengolahan data yang dilakukan diketahui bahwa penggunaan model pembelajaran Complete Sentence berbantu media audio visualefektif digunakan untuk mengajarkan materi sistem reproduksi manusia di kelas XI MIA MAN 1 Medan Tahun Pembelajaran 2017/2018. Adapun ringkasan pencapaian efektivitas model pembelajaran Complete Sentence berbantu media audio visual dapat di lihat pada Tabel 4 berikut ini.

Tabel 4. Pencapaian Efektivitas Pembelajaran Biologi

\begin{tabular}{lcc}
\multicolumn{1}{c}{ Kriteria } & Ket. & Kesimpulan \\
\hline $\begin{array}{l}\text { Tingkat } \\
\text { penguasaan } \\
\text { siswa } \\
\text { Ketuntasan } \\
\text { belajar siswa } \\
\text { Ketercapaian }\end{array}$ & Terpenuhi & \\
Indikator & Tuntas & Efektif \\
\hline
\end{tabular}

\section{KESIMPULAN}

Hasil belajar siswa yang diajar dengan menggunakan Model Pembelajaran Complete Sentence Berbantu Media Audio Visual pada Materi Sistem Reproduksi Manusia kelas XI MIA MAN 1 Medan Tahun Pembelajaran 2017/2018 memiliki nilai rata-rata 88.6 termasuk dalam kategori tuntas dengan standar deviasi 7.6. Aktivitas belajar siswa yang diajar dengan menggunakan Model Pembelajaran Complete Sentence Berbantu Media Audio Visual pada Materi Sistem Reproduksi Manusia kelas XI MIA MAN 1 Medan Tahun Pembelajaran 2017/2018 termasuk ke dalam kategori aktif karena skor rata-rata aktivitas belajar siswa mencapai nilai 75.55. Pembelajaran biologi dengan menggunakan model pembelajaran Complete Sentence berbantu media audio visual efektif digunakan pada materi sistem reproduksi manusia kelas XI MIA MAN 1 Medan Tahun Pembelajaran 2017/2018 dilihat dari tingkat penguasaan siswa mencapai 88.6 termasuk kategori tinggi, ketuntasan belajar siswa mencapai 91\% termasuk kategori tuntas, ketercapaian indikator mencapai 86.59 termasuk kategori tercapai, dan aktivitas belajar siswa yang mencapai 75.55 termasuk kedalam kategori aktif.

\section{DAFTAR PUSTAKA}

Arifin, Z., (2009), Evaluasi Pembelajaran, Bandung, Remaja Rosda Karya.

Fatimah, Nurul, (2016), Perbandingan Hasil Belajar Siswa Melalui Penggunaan Model Pembelajaran Kooperatif Tipe Concept Sentence dan Complete Sentence pada Subkonsep Vertebrata, Skripsi Prodi Pendidikan Biologi, UNPAS: Tidak Diterbitkan.

Fujiyanto, A., Jayadinata, A.K. dan Kurnia, D., (2016), Penggunaan Media Audio Visual untuk Meningkatkan Hasil Belajar Siswa pada Materi Hubungan Antar Makhluk Hidup, Jurnal Pena Ilmiah, 1(1) : 841-850.

Hariyatmi dan Syaifullah, A., (2016), Kemampuan Guru Biologi dalam Penerapan Kurikulum 2013 di SMA Negeri Se-Kabupaten Pekalongan, Proceeding Biology Education Conference, 13(1) : 225-231. 
Hasruddin, Batubara, A.N., dan Mulyana, R., (2016), Pengaruh Strategi Pembelajaran Inkuiri dan Discovery terhadap Kemampuan Berpikir Kritis dan Hasil Belajar Biologi Siswa pada Topik Bioteknologi di MAN I Padangsidimpuan, Jurnal Pendidikan Biologi, 5(2) : 74-81.

Mukti, I. N. C., dan Nurcahyo, H., (2017), Pengembangan Media Pembelajaran Biologi Berbantuan Komputer untuk Meningkatkan Hasil Belajar Peserta Didik, Jurnal Inovasi Pendidikan IPA, 3(2), 137-149.

Marumu, M.Dg., (2015), Penggunaan Model Complete Sentence untuk Meningkatkan Hasil Belajar Listening Siswa Kelas IX C SMP Negeri 2 Tolitoli. Jurnal Kreatif Tadulako Online, 4(5) : 292-301.

Pujiati, I., (2008), Peningkatan Motivasi dan Ketuntasan Belajar Matematika Melalui Pembelajarankooperatif Tipe STAD, Jurnal IImiah Kependidikan, (1)1 : 1-20.

Slameto, (2015), Belajar dan Faktor-faktor yang Mempengaruhi, Jakarta, Penerbit Rineka Cipta.

Suharno, (2014), Implementasi Pembelajaran Berbasis Kurikulum 2013 pada matapelajaran Biologi di SMA Negeri 1 Gondang Kabupaten Tulung Agung, Jurnal Humanity, 10(1) : 147-157.

Supardi., (2013), Sekolah Efektif: Konsep Dasar dan Praktiknya, Jakarta, Rajawali Press.

Suryosubroto., A, (2007), Proses Belajar Mengajar Disekolah, Jakarta, Rineka cipta.

Utami, F.L., Kholillah, dan Aseptianova, (2012), Studi Perbandingan Media AudioVisual dengan Media Berbasis Lingkungan Sekolah terhadap Hasil Belajar Siswa Biologi pada Materi Keanekaragaman Hayati di SMA Negeri 2 Palembang, Jurnal Kognisi, 3(2) : 5663.

Siswa pada Pembelajaran Biologi Melalui Implementasi Model Number Head Together pada Siswa Kelas XI SMA
Negeri 2 Yogyakarta, Jurnal pendidikan matematika dan sains, 3(1): 65-71.

Winarti, C., (2017), Penerapan Model Pembelajaran Complete Sentence dalam Meningkatkan Keterampilan Menulis Karangan, E-Journal.UPI.EDU, 4(3): 256-263. 